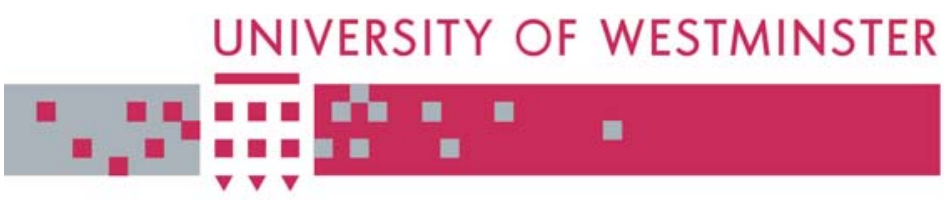

\title{
WestminsterResearch
}

http://www.wmin.ac.uk/westminsterresearch

\section{Design of generalized Chebyshev lumped element filters by computer optimisation.}

\author{
Djuradj Budimir \\ Laleh Lalehparvar \\ Natasa Nikolic
}

School of Informatics, University of Westminster

Copyright (C) [2002] IEEE. Reprinted from the proceedings of the 11th Mediterranean Electrotechnical Conference, 2002. MELECON 2002, pp. 475478.

This material is posted here with permission of the IEEE. Such permission of the IEEE does not in any way imply IEEE endorsement of any of the University of Westminster's products or services. Internal or personal use of this material is permitted. However, permission to reprint/republish this material for advertising or promotional purposes or for creating new collective works for resale or redistribution must be obtained from the IEEE by writing to pubs-permissions@ieee.org. By choosing to view this document, you agree to all provisions of the copyright laws protecting it.

The WestminsterResearch online digital archive at the University of Westminster aims to make the research output of the University available to a wider audience. Copyright and Moral Rights remain with the authors and/or copyright owners.

Users are permitted to download and/or print one copy for non-commercial private study or research. Further distribution and any use of material from within this archive for profit-making enterprises or for commercial gain is strictly forbidden.

Whilst further distribution of specific materials from within this archive is forbidden, you may freely distribute the URL of the University of Westminster Eprints (http://www.wmin.ac.uk/westminsterresearch). 


\title{
Design of Generalized Chebyshev Lumped Element Filters by Computer Optimisation
}

\author{
D. Budimir, L. Lalahparvar and N. Nikolic \\ Wireless Communications Research Group, Department of Electronic Systems, \\ University of Westminster, 115 New Cavendish Street, \\ London W1W 6UW, United Kingdom. \\ Tel: +44 207 9115139; Fax: +44 2079115089 \\ budimid@wmin.ac.uk
}

\begin{abstract}
A numerical method for the optimization of a symmetrical lumped element lowpass. and bandpass filters with Generalized Cheyshev response is considered. By exploiting the fact that a network based on generalized Chebyshev prototype has a prescribed number of turning points in the insertion loss and an identical number of independent parameters which can be assigned os variables to adjust their levels the method gives fast convergence.
\end{abstract}

Key-Words: - Low-pass Filters, Bandpass Filters, LC Filters, Lumped Element, Generalized Chebyshev Filters, Optimization

\section{INTRODUCTION}

When a common approach to the design of filters results in a design passband which differs considerably from that which is specified, optimization is required to tune the filter elements to achieve a design that meets certain requirements. Most RF and microwave filters have not yielded exact optimum synthesis. Taking into account parasitic effects; high frequency operation, frequency dependent elements, a narrow range of element values, and so on, a common approach to design provides, at best, only approximate answers. Not infrequently, a common approach may be used to great advantage in providing the initial points for optimization. In this paper, we introduce an optimization procedure based on equal ripple optimisation to optimise filters based upon Generalized Chebyshev function prototype.
This method searches for tuning points in the filter transfer function and forces the ripple levels at these points to have specified values. The method requires knowledge of the filter insertion or return loss at these points.

The method will generate a set of equations which are solved to give a new set of parameter values. The cycle is then repeated; until the filter characteristic is within an arbitrarily close value to the desired specification. This technique requires less calculation of the electrical parameters of filter discontinuity than generalised optimization routines so far applied [1].

\section{PROBLEM FORMULATION}

The double terminated low-pass prototype network shown in Figure 1 satisfies a generalized Chebyshev insertion loss response.

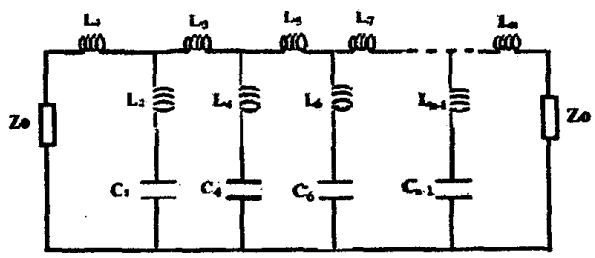

Figure 1. Generalised Chebyshev low pass prototype

This characteristic in terms of insertion loss, $L$, is given by

$L=1+\varepsilon^{2} \cosh ^{2}\left\{(n-1) \cosh ^{-1}\left[u\left(\frac{w_{0}^{2}-1}{\frac{2}{w_{0}^{2}-w^{2}}}\right)^{\frac{1}{2}}\right]+\cosh ^{-1} w\right\}$

where the transmission zeros are of order $(n-1)$ at 
$w= \pm w_{o}$ and one at infinity. $n$ is an odd number equal to the degree of the network, $\varepsilon=\left[10^{(R \cdot L / 10)}-1\right]^{-\frac{1}{2}}$ and R.L. is the minimum return loss level (dB) in the passband.

A typical insertion loss response is illustrated in Figure 1a, where $w_{m}$ is the frequency of the minimum insertion loss level in the stopband and $w_{1}$ is the bandedge frequency of the stopband.

In general, approximate methods based on the synthesis of a generalized Chebyshev prototype to the design a symmetrical filter will not meet the specifications satisfied by. (1). Assume that an $n$th degree symmetrical low-pass filter has an insertion loss response $L_{I}$ of the form shown in Figure 1a. It exhibits $m-1 \quad(m=n-I)$ zeros and $m-2$ ripples, the maxima of which occur at the frequencies $f_{2}, f_{3}, \ldots f_{m}$

For a symmetrical low-pass filter all of these $m-2$ frequencies lie within the specified passband $f_{l} \Rightarrow f_{\nu}$. The deviation of a ripple maximum from the maximum allowed insertion loss in the passband, $L_{l}$, is a function of the $m=n+1$. symmetrical filter parameter values required to specify the low-pass filter. There are $n-1$ such functions for the symmetrical case:

$E=L\left(f_{i}\right)-L_{r r}, i=12,3 \ldots-3$

$E_{c}$ and $E_{m}$ are defined by:

$$
\begin{aligned}
& E_{c}=L_{l}\left(f_{c}\right)-L_{b} \\
& E_{m}=L_{l}\left(f_{u}\right)-L_{m} .
\end{aligned}
$$

$E_{o} E_{m}$ are also functions of the $m=n-1$ parameter values of the symmetrical filter.

The specifications

$$
\begin{array}{ll}
L_{I}(f) \leq L_{t r} & , 0 \leq f \leq f_{c} \\
L_{l}(f) \geq L_{m} & , f_{o} \leq f \leq f_{m}
\end{array}
$$

are satisfied when

$$
E_{i}=0, \quad i=1,2,3 \ldots . . m
$$

This is a system of $m=n-1$ nonlinear equations in $m=n-I$ variables for the symmetrical case. Solving (6) gives the parameter values of a filter satisfying (5). The $E_{l}(i=1, \ldots, m)$ can be reganded as the components of an $m$ dimensional error vector. Optimization is carried out by equating each of these components to zero (a vector process) rather than minimizing the magnitude of the vector (a scalar process). Thus equal ripple optimization can be reganded as a vector procedure whereas general purpose optimization routines are scalar procedures. Usually the convergence criterion applied in general pupose optimization routines is that the gradient, with respect to the filter elements, of the magnitude of the error vector is zero. However a zero gradient may correspond to a local minimum and the error may not be truly minimized. The convergence criterion applied in equal ripple optimization is that each component of the error vector is zero. Thus on convergence the error is reduced to zero. The problem of local minima does not arise..

To apply an iterative nonlinear equation solver it is necessary for a given set of filter parameter values to know the insertion loss only at the bandedge frequency, $f_{m}$ (minimum) and at the ripple maxima. However, the frequencies at which the ripple maxima occur are unknown and are finctions of the filter parameter values.

The Newton-Raphson method [4] is a rapidly convergent technique for the solution of a system of nonlinear equations if a good initial approximation is available. The number of times the finction is evaluated in the process of finding its root is the usual measure of computational effort. This includes function evaluations required to calculate derivatives numerically.

The Newton-Raphson method has the general form [5]

$$
\mathrm{x}^{k}=\mathrm{x}^{k-1}-\mathrm{J}^{-1}\left(x^{k-1}\right) \mathrm{E}\left(x^{k-1}\right)
$$

where $k$ is the iteration number $(k=1,2, \ldots)$ and $J^{\prime}$ is the inverse of the $m \times m$ Jacobian matrix evaluated at $x^{k-1}$. The above identifies the regions within the passband which need to be sampled in order to calculate $E\left(x^{k}\right)$ (and $J\left(x^{k}\right)$ ). The response and errors after each iteration are computed again with the new corrected parameters, until the errors are judged to be sufficiently small. 


\section{NUMERICAL RESULTS}

In order to illustrate our approach, a fifth order lumped element low-pass and band-pass filters have been designed. The low-pass filter can be described by 4 parameters: inductors ( $L 1=L 5$, $\mathrm{L} 2=\mathrm{L} 4, \mathrm{~L} 3)$ and capacitor $(\mathrm{C} 2=\mathrm{C} 4)$ as marked in Figure 2. We used equal ripple optimization with $L 1, L 2, L 3$ and $C_{2}$ as variables for filter shown in Figure 2. Figure 3 a shows the calculated return loss (dasbed line) and insertion loss (solid line) of filter before optimization. The return loss (dashed line) and insertion loss (solid line) calculated using the filter elements obtained on convergence are shown in Figure 3b. The band-pass filter can be described by 6 parameters: inductors $(L 1=L 5$, $\left.L_{2}=L A, L 3\right)$ and capacitors $(C 1=C 5, C 2=C 4, C 3)$ as marked in Figure 4. We used equal ripple optimization with $\mathrm{Ll}, \mathrm{L} 2, \mathrm{L3}$ and $\mathrm{Cl}, \mathrm{C} 2, \mathrm{C}_{3}$ as variables for filter shown in Figure 4. Figure 5 a shows the calculated return loss (solid line) and insertion loss (dashed line) of filter before optimization. The return loss (solid line) and insertion loss (dasbed line) calculated using the filter elements obtained on convergence are shown in Figure $\mathbf{5 b}$

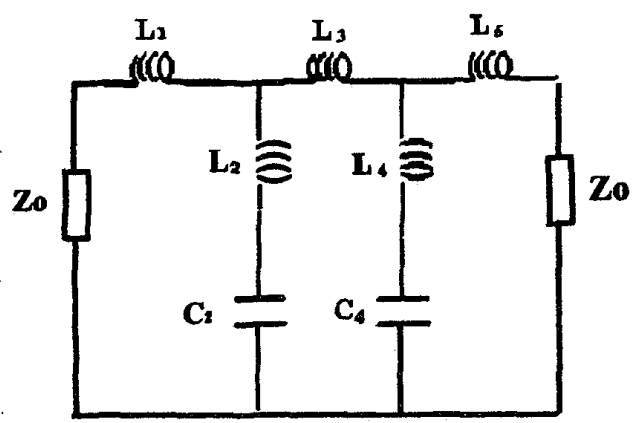

Figure 2. Generalized Chebysher low-pass filter

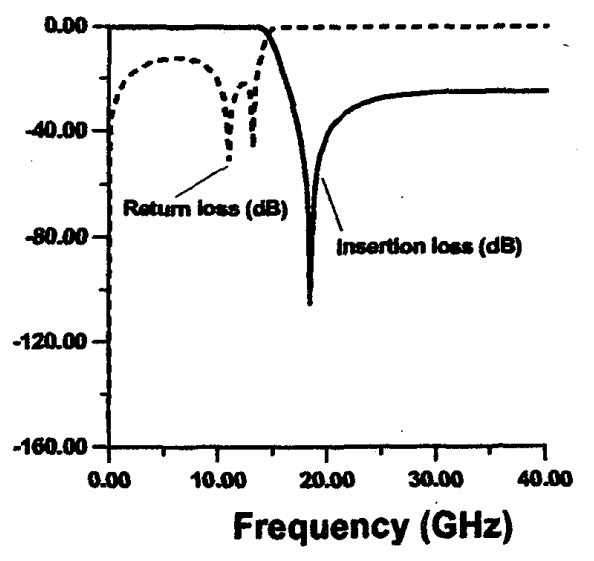

Figure 3a. Simulated Insertion and Return loss of generalized Chebyshev low pass filter before optimization

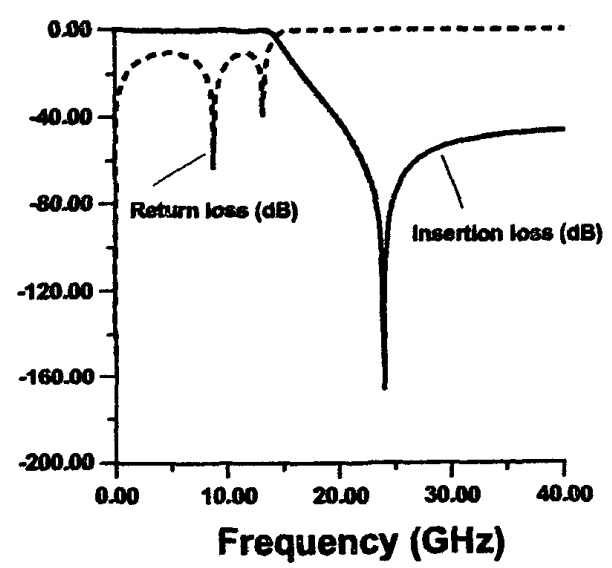

Figure 3b. Simulated Insertion and Return loss of generalized Chebyshev low pass filter after optimization

C1 Li

$\mathrm{C}_{3} \mathrm{~L}_{3} \mathrm{C}_{5} \mathrm{~L}_{\mathrm{s}}$

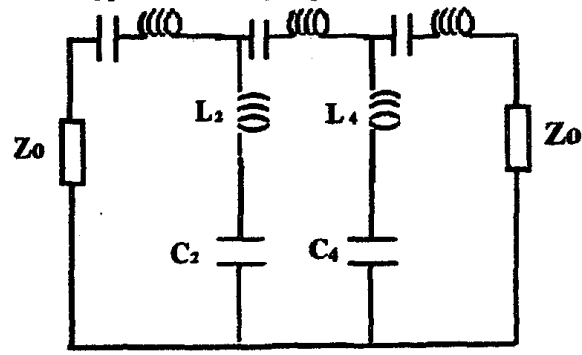

Figure 4. Generalized Chebyshev band-pass filter 


\section{References}

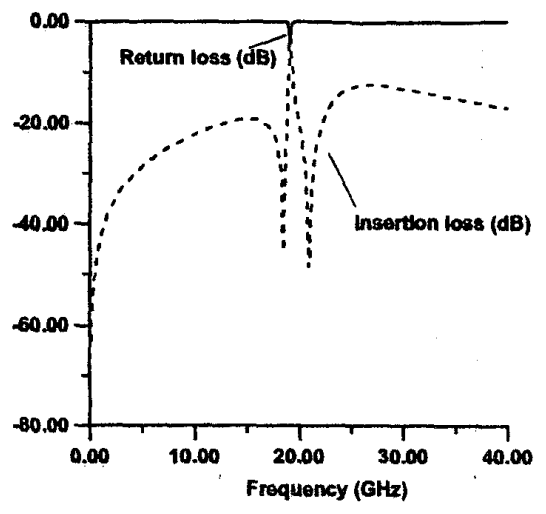

Figure 5a. Simulated Insertion and Return loss of generalized Chebyshev band-pass filter before optimization

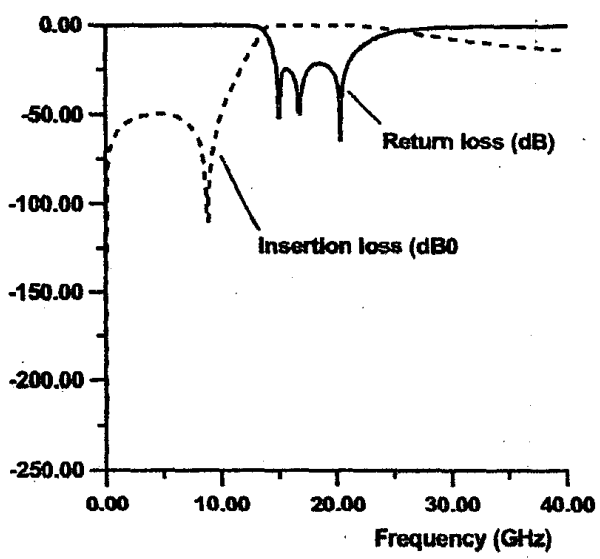

Figure 5b. Simulated Insertion and Return loss of generalized Chebyshev band pass filter after optimization

\section{CONCLUSION}

The method presented here offers a simple but reliable method for optimization of low-pass and band-pass filters with Generalized Chebyshev function prototype. The method provides fast convergence.
[1] Bandler, J. W., and S.H. Chen, "Circuit Optimization: The State of the Art," IEEE Trans.Microwav Theory \& Tech., Vol.MTT36,1988, pp.424-443.

[2] Rhodes J. D. and S. A. Alseyab, "The Generalized Chebyshev Low-pass Prototype Filten, Mciowave Theory and Applications, icrowave Journal., September 1989, pp.197-201

[3] .Budimir, D., "Generalized Filter Design by Computer Optimization", ISBN 0-89006579-9, Artech House Books, 1998.

[4]. Gupta K. C, R.Garg and R.Chadha, "CAD of Microwave Circuits", Artech House, Dedham MA, 1981. 